\title{
Daming capsule restores endothelial dysfunction induced by high-fat diet
}

\author{
Rong Zhang ${ }^{1 \dagger}$, Huifang $\mathrm{Niu}^{1 \dagger}$, Ning Wang ${ }^{1}$, Lihua Sun ${ }^{1}, \mathrm{Yi}_{\mathrm{i}} \mathrm{Xu}^{1}$, Ruibo Zhao ${ }^{1}$, Xiang Ban², Yao Yu², Baofeng Yang \\ and Jing $\mathrm{Ai}^{1 *}$
}

\begin{abstract}
Background: Daming capsule (DMC), a traditional Chinese formula, has a lipid-modulating action with reduced adverse side effects as compared with other lipid lowering compounds. Since endothelial dysfunction often accompanies the hyperlipidemic state, we hypothesize that DMC might restore endothelial dysfunction produced by a high-fat (HF) diet. Importantly, we also investigate possible mechanisms involved in mediating the effects of DMC on vascular reactivity.

Methods: Rats were divided into four groups: control, HF diet, HF mixed DMC diet, HF mixed atorvastatin (ATV) diet. After 30 days, the thoracic cavity was exposed to remove the thoracic aorta for (i) histological examination; (ii) measurement of endothelial nitric oxide synthase (eNOS) by western blot; and (iii) tension study of thoracic aortic ring.

Results: HF diet induced significant attenuation in the contraction and relaxation of rat aortic rings. Treatment with DMC significantly improved the relaxation of the aortic rings as compared with those from HF rats $(P<0.05)$, which was abolished by a nonspecific NOS inhibitor L-NAME. Moreover DMC significantly restored the decrease in eNOS expression induced by HF diet. Similar results were found in histopathologic changes. DMC failed to restore the loss of vasocontraction of aorta explained by an impairment of ATP-sensitive $K^{+}$channels ( $K_{\text {ATP }}$ ) on the structure and/or function. DMC exerted the same protective effect as ATV, a positive control drug, on vascular injury produced by HF diet.
\end{abstract}

Conclusion: DMC partially protects the aorta from HF-induced endothelial dysfunction via upregulation of the expression of eNOS.

\section{Background}

Hyperlipidemia is an important independent risk factor for cardiovascular diseases. Hyperlipidemia is accompanied by vascular disease such as: atherosclerosis, angiostenosis and blocking, which may induce hypertension, cerebral apoplexy, myocardial infarction, and even sudden cardiac death. Accumulating evidence indicates that a high-fat diet induces both systemic and tissue oxidative stress and the development of early vascular lesions [1]. Impaired endothelial function, an early hallmark of atherogenesis, was observed in rats and healthy

\footnotetext{
* Correspondence: a.z.hrbmu@gmail.com

+ Contributed equally

'Department of Pharmacology, (the State-Province Key Laboratory of Biomedicine and Pharmaceutics), and Key Laboratory of Cardiovascular Research, Ministry of Education, Harbin 150086, Peoples' Republic of China Full list of author information is available at the end of the article
}

volunteers fed high-saturated fat and high-sucrose meals $[2,3]$. Moreover, nitric oxide (NO) produced by endothelium was inhibited by high-fat diet [4]. Hyperlipidemia and oxidation of low density lipoprotein (LDL) induce vascular smooth muscle cell growth [5] and hyperlipidemia may alter the vascular response to vasodilators [6]. The regulation of vascular tone is important for maintaining adequate perfusion to critical organs and is regulated by factors released from the endothelium and by other components such as receptors, ion channels and signaling pathways $[7,8]$. Therefore, it's valuable to investigate the mechanisms of various compounds on controlling vessel tone in vessel-related diseases.

Compared with Western medicine, the traditional Chinese medicine formula has a prominent advantage due to a stable curative effect with reduced toxicity. It simultaneously targets multiple physiological processes to
C Biomed Central

(C) 2012 Zhang et al; licensee BioMed Central Ltd. This is an Open Access article distributed under the terms of the Creative Commons Attribution License (http://creativecommons.org/licenses/by/2.0), which permits unrestricted use, distribution, and reproduction in any medium, provided the original work is properly cited. 
arouse the whole body's potentiality to recover to health. The traditional Chinese medicine compatibility emphasizes jun, chen, zuo, shi (monarch, minister, adjuvant and messenger) with proper herbs and relevant dosage to synergize the desirable effects and minimize side effects integrally [9]. Daming capsule (DMC) was designed and carefully formulated in accordance with the rule of the traditional Chinese medicine theory comprising: Rheum Palmatu, Cassia obtusifolia L, Salvia miltiorrhiza and Panax ginseng C.A.. Rheum Palmatu is regarded as monarch component for its actions on promoting digestion to remove food retention and improving blood circulation to dissipate blood stasis (Pharmacopoeia of the People's Republic of China, 2010). Cassia obtusifolia L, Salvia miltiorrhiza and Panax ginseng C.A. are considered as minister or adjuvant components to enhance the pharmacological functions and compensate for the side effects of Rheum Palmatu [9]. Our previous clinical study reported that DMC had a lipid-lowering action with lower adverse side effects and significantly decreased serum total cholesterol and LDL cholesterol indicating that it might be a good candidate for the treatment of hyperlipidemia [10]. Further study demonstrated that DMC could reverse the prolonged QT and PR interval and improve heart function [9] and also restored impaired baroreflexes in STZ-induced diabetic rats with hyperlipidemia [11]. There is no report related to the role of DMC on the regulation of vascular morphology or function that is negatively impacted by hyperlipidemia. This study was designed to investigate whether DMC has effects on vascular reactivity and to test the hypothesis that DMC may affect endothelial nitric oxide synthase (eNOS) in endothelium and in turn contribute to the restoration of endothelial dysfunction of aorta from rats fed a high-fat (HF) diet.

\section{Methods}

\section{Chemicals and herbal materials}

The formula of DMC was designed by Professor Baofeng Yang in the department of Pharmacology of Harbin Medical University (Patent No.: ZL03109063.X) and produced by Harbin Yida Ltd as reported in our previous publications [9-11]. Briefly, the plants were harvested from corresponding provinces and collected at appropriate season. The grounded powders were capsulated at a ratio of 12:12:6:1 of Rheum Palmatu, Cassia obtusifolia L, Salvia miltiorrhiza and Panax ginseng C.A.. The entire process was supervised according to the policy of the State Food and Drug Administration of P.R.China. Quality control was performed by marker compound chrysophanol using HPLC analysis to quantify total anthraquinones in DMC. The content of chrysophanol was more than 1.5 $\mathrm{mg}$ in each capsule $(300 \mathrm{mg})$ estimated from standard calibration curve. Atorvastatin (ATV) was purchased from Huirui Pharmaceutical Co., Ltd., China. All reagents used in our vascular reactivity studies were purchased from Sigma, Saint Louis, MO, USA.

\section{Animals}

Male Wistar rats (200-230 g, $n=40)$ were obtained from the Animal Center of the 2nd Affiliated Hospital of Harbin Medical University, China, and housed in a room with controlled temperature of $23 \pm 1^{\circ} \mathrm{C}$ and humidity of $55 \pm 5 \%$ under a 12 h-12 h light-dark cycle. All experimental procedures and protocols used in this investigation received approval by the ethic committees of Harbin Medical University.

\section{Establishment of HF model}

The HF emulsion was prepared as previously described [9-11]. Fat emulsion comprised lard (20\%), thyreostat (1\%), cholesterol (5\%), sucrose (5\%), saccharu (5\%) and sodium glutamate (1\%) in 20\% Tween 80 and $30 \%$ (v/v) propylene glycol. The diet was kept at $4^{\circ} \mathrm{C}$ before use. Rats were randomly divided into four groups $(n=10$ in each group) as follows: control group, HF group, HF + DMC $(100 \mathrm{mg} / \mathrm{kg} / \mathrm{d}$, the optimal dose from previous study [9]) group and HF + ATV $(7.2 \mathrm{mg} / \mathrm{kg} / \mathrm{d}$, dissolved with $0.5 \%$ carboxymethylcellulose sodium) group. The control group received $0.9 \% \mathrm{NaCl}(10 \mathrm{ml} / \mathrm{kg} / \mathrm{d})$ and the $\mathrm{HF}$ rats received the $\mathrm{HF}$ emulsion $(10 \mathrm{ml} / \mathrm{kg} / \mathrm{d})$ by intragastric administration for 30 days. DMC and ATV was mixed in HF emulsion and administered to the rats in DMC treated group and ATV treated group, respectively.

\section{Vascular reactivity studies and experimental protocols}

These studies were performed as previously described [12]. Briefly, the thoracic cavity was exposed to remove the thoracic aorta in anesthetized rats. Adherent fat and connective tissue was cleaned from aortas which were used for: (i) histological examination; (ii) measurement of eNOS by western blot; and (iii) tension study of thoracic aortic ring. Aortas were cut into rings $(2-3 \mathrm{~mm})$, mounted on a force transducer placed in an organ bath having $\mathrm{pH}$-adjusted, oxygenated Ringer's solution (mM: $\mathrm{NaCl} 118, \mathrm{KCl} 4.7, \mathrm{MgSO}_{4} 0.6, \mathrm{KH}_{2} \mathrm{PO}_{4} 1.18, \mathrm{CaCl}_{2} 2.5$, glucose 10 and $\mathrm{NaHCO}_{3} 27, \mathrm{pH} 7.4$ ) at $37^{\circ} \mathrm{C}$. Rings were initially loaded with $1.5 \mathrm{~g}$ tension (basal tension) by incremental application over $30 \mathrm{~min}$ and then equilibrated for an additional 30-40 min before the studies were started. A dose-dependent constriction to phenylephrine (PE) $\left(10^{-6} \mathrm{M}\right.$ to $\left.10^{-5} \mathrm{M}\right)$ followed by measurement of vasorelaxation in response to acetylcholine (ACh) $\left(10^{-5} \mathrm{M}\right.$ to $\left.10^{-4} \mathrm{M}\right)$ was examined. Aortic rings were washed repeatedly with Ringer's solution until tone recovered to basal level and then treated with different inhibitors according to protocols as follows. Reactivity 
of the rings was again measured to $10^{-5} \mathrm{M} P E$ and $10^{-4}$ $\mathrm{M}$ ACh. Vasorelaxation to ACh was calculated as (tension $\mathrm{PE}$ - tension $\mathrm{ACh}$ )/tension $\mathrm{PE}$ (the percent change in reactivity to $10^{-4} \mathrm{M} \mathrm{ACh}$ after $\left.10^{-5} \mathrm{M} \mathrm{PE}\right)$. At termination of the experiment, $\mathrm{KCl}(60 \mathrm{mM})$ was applied to detect the non-receptor mediated response of the rings. Tension data were relayed from the pressure transducers to a signal amplifier. BL-420E + signal analysis software (Chengdu, China) was employed to describe the isometric changes in force of the aortic rings.

Protocol 1: To determine the effect of $\mathrm{K}^{+}$channels, 4amionpyridine (4-AP, $3 \mathrm{mM}, \mathrm{K}_{\mathrm{V}}$ channel blocker), tetraethylammonium (TEA, $1 \mathrm{mM}, \mathrm{BK}_{\mathrm{Ca}}$ channel blocker) or glyburide (GLYB, $1 \mu \mathrm{M}, \mathrm{K}_{\mathrm{ATP}}$ channel blocker) were pre-incubated for 30 min respectively before adding PE and $\mathrm{ACh}$.

Protocol 2: To determine the effect of eNOS, $\mathrm{N}^{\mathrm{G}}$ Nitro-L-arginine Methyl Ester (L-NAME, $10^{-4} \mathrm{M}$, a nonspecific NOS inhibitor) was pre-incubated for $30 \mathrm{~min}$ before adding $\mathrm{PE}$ and $\mathrm{ACh}$.

\section{Histology}

The thoracic aorta segments were taken and fixed in zinc formalin for 24 to $48 \mathrm{~h}$ then processed using a Sakura Tissue Tek VIP5 processor. Processing was performed using 70\%, 80\%, 95\% and 100\% ethanols, xylene and paraffin. Following processing, samples were oriented (embedded) in paraffin and sectioned at $4 \mu \mathrm{m}$ using a microtome. Sections were stained with hematoxylin and eosin (H\&E) for histological examination.

\section{Western blot analysis}

The thoracic aorta segments were homogenized in lysis buffer (RIPA buffer $60 \%$, SDS $40 \%$ and protease inhibitor cocktail 1\%) on ice, then centrifuged at $14,000 \mathrm{rpm}$ at $4^{\circ} \mathrm{C}$ for $30 \mathrm{~min}$ to remove the insoluble pellet. Protein concentration in the supernatant was determined by the Biorad DC Protein Assay (Biorad, Hercules, CA, USA). Equal amounts of protein $(60 \mu \mathrm{g})$ were loaded on $8 \%$ SDS-PAGE gel. The lysates were resolved by electrophoresis (100 V for $1 \mathrm{~h}$ ) and transferred onto nitrocellulose membranes. After being blocked in 5\% nonfat milk for $2 \mathrm{~h}$, the membranes were treated with primary antibody for rabbit anti-eNOS (sc-654, Santa cruz, CA, USA), overnight at $4^{\circ} \mathrm{C}$ and washed 5 times before incubating with secondary antibody (1:2000) for $1 \mathrm{~h}$. Blots were detected with the Odyssey infrared imaging system (Licor, USA). Protein loading was confirmed using GAPDH (1:2000, Sigma, Saint Louis, MO, USA) as an internal control.

\section{Statistical analysis}

Data were calculated as means \pm S.E.M (standard error of the means). The changes in vasoreactivity were expressed as the percent increase in tone from the baseline. The differences in mean values among the experimental groups were measured using two-tailed analyses of variance (ANOVA) followed by Dunnetts's test. Differences were considered statistically significant at $P<$ 0.05 .

\section{Results}

The dose-response reactivity curves to $\mathrm{PE}$ and $\mathrm{ACh}$ in aortic rings

In vascular reactivity studies increasing concentrations of $\mathrm{PE}$ and $\mathrm{ACh}$ were applied to detect vascular contraction and relaxation, respectively. Aortic rings exhibited dose-dependent contraction and relaxation to PE $\left(10^{-6}\right.$ $\mathrm{M}$ to $\left.10^{-5} \mathrm{M}\right)$ and $\mathrm{ACh}\left(10^{-5} \mathrm{M}\right.$ to $\left.10^{-4} \mathrm{M}\right)$, respectively (Figure 1A, typical tracing of vascular reactivity), indicating that $10^{-5} \mathrm{M} \mathrm{PE}$ and $10^{-4} \mathrm{M} \mathrm{ACh}$ were maximal and therefore these concentrations were used in the remaining experiments. As shown in Figure $1 \mathrm{~B}$ and $1 \mathrm{C}$, the vascular contraction and relaxation were significantly attenuated in rats fed a HF diet (124.76 \pm 4.6 vs. 183.66 \pm 7.72 in contraction, $P<0.01 ; 9.09 \pm 1.03$ vs. $26.14 \pm$ 2.47 in relaxation, $P<0.01)$. Treatment with $\mathrm{DMC}$ did not improve the loss of vasocontraction $(132.3 \pm 3.48)$ but significant mitigation was seen in the relaxation of the aortic rings from DMC treated group (18.59 \pm 1.31 vs. $9.09 \pm 1.03, P<0.01)$. Same result was obtained from ATV treated rats $(130.45 \pm 3.42$ in contraction, $17.74 \pm 2.2$ in relaxation). Figure $1 \mathrm{D}$ showed the typical tracing of vascular reactivity with $\mathrm{KCl}$. A similar trend of vasocontraction was observed if those rings exposed to $60 \mathrm{mM} \mathrm{KCl}$ (Figure 1E).

\section{The influence of $\mathrm{K}^{+}$channels on the contraction of aortic rings}

As shown in Figure 2A, pre-incubation of 4-AP, a $\mathrm{K}_{\mathrm{V}}$ channel blocker, significantly increased contraction of aortic rings in control rats, indicating that $\mathrm{K}_{\mathrm{V}}$ channels were involved in the process of constriction. Similar results were observed in $\mathrm{HF}, \mathrm{DMC}$ and ATV treated rats, suggesting $K_{V}$ channels play the same role in all groups. Pre-incubation of GLYB, a $K_{\text {ATP }}$ channel blocker, significantly enhanced the vasocontraction in control rats but not in the other groups. These results demonstrate that blockade of $\mathrm{K}_{\mathrm{ATP}}$ channels affected vasoconstriction of rats fed a HF diet. The structure and/or function of $\mathrm{K}_{\mathrm{ATP}}$ channels may thus be altered in HF model and were not improved by the treatment of DMC and ATV. There was no change of vasocontraction in all groups after pre-incubation of TEA, $\mathrm{BK}_{\mathrm{Ca}}$ channel blocker, indicating $\mathrm{BK}_{\mathrm{Ca}}$ channels were not involved in the contraction of aortic rings. The relaxation of aortic rings of four groups weren't changed after pre-incubation of $\mathrm{K}^{+}$channel blockers (Figure $2 \mathrm{~B}$ ). 


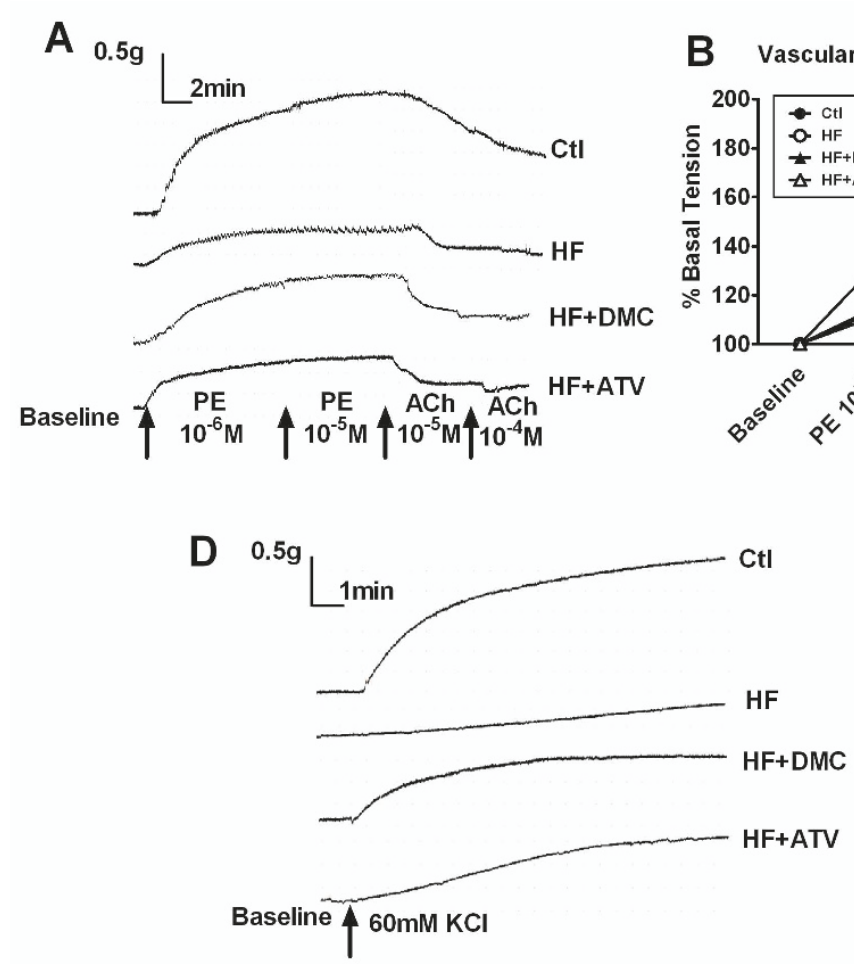

C Percent change in reactivity with $10^{-4} \mathrm{M} \mathrm{ACh}$ after $10^{-5} \mathrm{M} \mathrm{PE}$
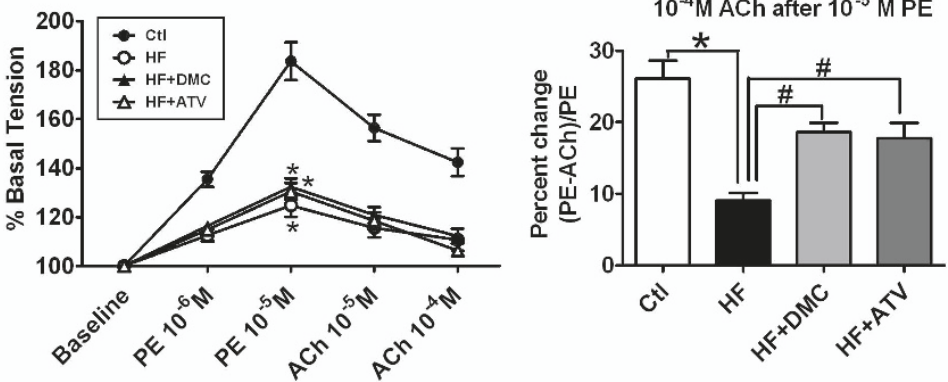

Figure 1 High-fat-induced loss of vascular reactivity of aortic rings and mitigation by DMC and ATV. (A) Typical tracing and (B) Representative line graph showing increased contraction and relaxation by increasing concentration of PE and ACh. (C) The percent change in relaxation ((tension PE - tension Ach)/tension PE) to $10^{-4} \mathrm{M}$ ACh after $10^{-5} \mathrm{M} \mathrm{PE}$. (D) Typical tracing and (E) Vascular tension to $60 \mathrm{mM} \mathrm{KCl}$ in all groups. Data presented as mean \pm S.E.M. and expressed as percentage of baseline tension. ${ }^{*} P<0.01 \mathrm{vs}$. control group, \# $P<0.05 \mathrm{vs}$. HF, $n=$ 16-18 rings from 6-7 rats.
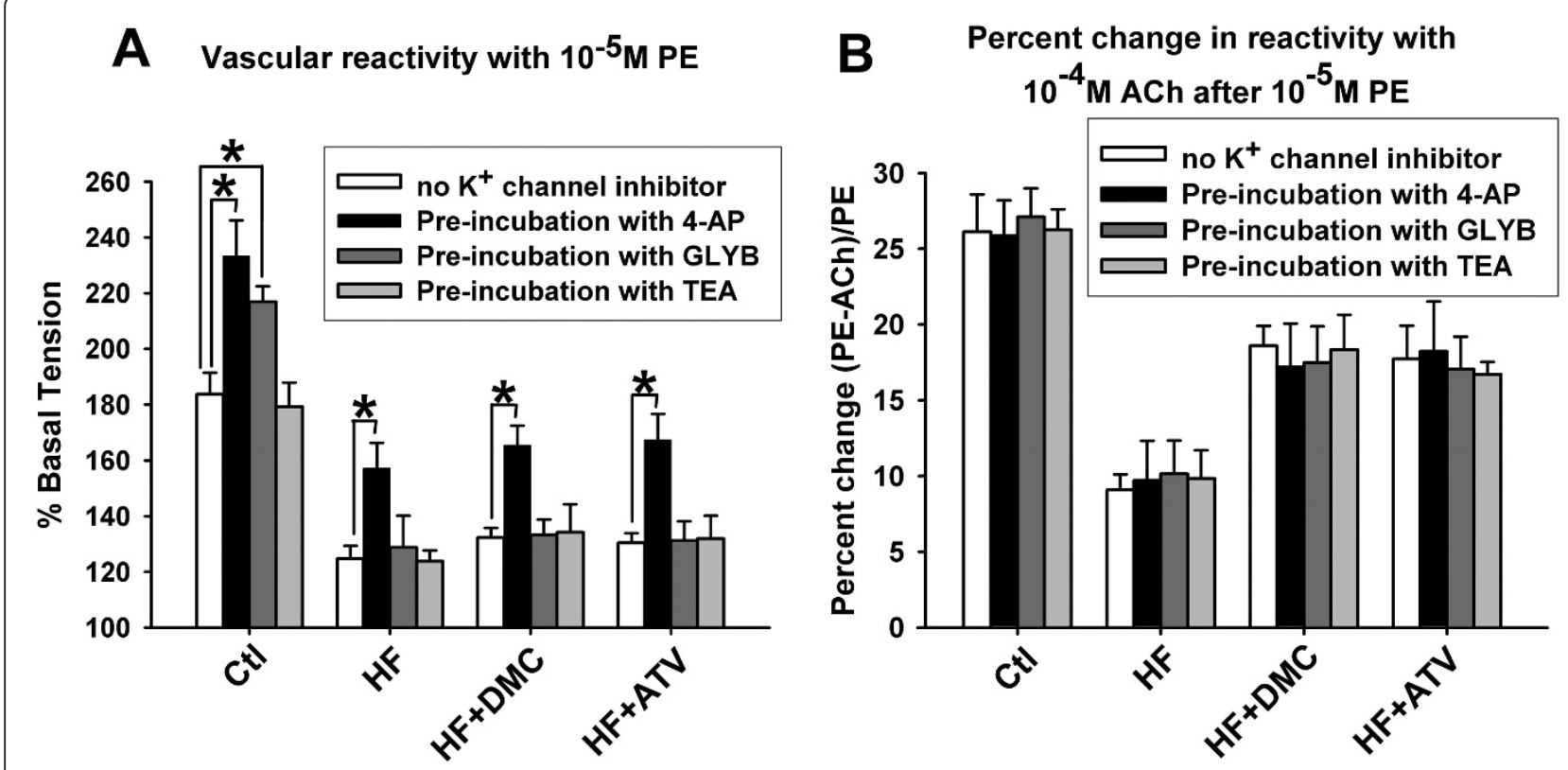

Figure $\mathbf{2}$ Effect of $\mathrm{K}+$ channels on the contraction of aortic rings. (A) The contraction of aortic rings with $10^{-5} \mathrm{M}$ PE before and after preincubation with 4-AP, $3 \mathrm{mM}, \mathrm{K}_{\mathrm{V}}$ channel blocker; TEA $1 \mathrm{mM}, \mathrm{BK}_{\mathrm{Ca}}$ channel blocker and GLYB, 1 MM, $\mathrm{K}_{\mathrm{ATP}}$ channel blocker respectively for 30 min. (B) The percent change in relaxation ((tension PE - tension Ach)/tension PE) to $10^{-4} \mathrm{M} \mathrm{ACh}$ after $10^{-5} \mathrm{M}$ PE before and after pre-incubation with three $\mathrm{K}^{+}$channel blockers respectively. Data presented as mean \pm S.E.M. and expressed as percentage of baseline tension. ${ }^{*} P<0.01$ vs. contraction value of corresponding group before pre-incubation of $\mathrm{K}^{+}$channel blocker, $n=8-10$ rings from 5-6 rats. 
The effect of eNOS on the relaxation of aortic rings Pre-incubation with L-NAME (a non-selective NOS inhibitor) did not alter the contraction of rings to $\mathrm{PE}$ significantly in all groups (Figure 3A). After applying ACh there was a significant attenuation of relaxation in control $(15.15 \pm 2.57$ vs. $26.14 \pm 2.47, P<0.01)$, DMC treated rats $(11.92 \pm 1.25$ vs. $18.59 \pm 1.31, P<0.01)$ and ATV treated rats $(12.55 \pm 1.38$ vs. $17.74 \pm 2.2, P<0.01)$ but not in those fed a HF diet $(8.21 \pm 1.16$ vs. $9.09 \pm$ 1.03) (Figure 3B). These data supported the idea that eNOS participated in the relaxation of aortic rings in control, DMC and ATV treated rats. However, HF diet affected eNOS via a certain mechanism.

\section{Histological characters of aortas}

Representative histological sections of aorta were shown in Figure 4. Figure 4A showed the normal structure of the control aorta. Considerable damage in endothelial cells was noted in HF group such as disordered arrangement, unclear borderline, and even partial deletion. There was no change in the layer of smooth muscle (Figure 4B). In DMC and ATV treated groups, these pathological injuries in endothelial cells were recovered to normal (Figure 4C, D).

DMC restored eNOS expression in aortic endothelial cells attenuated by HF diet

eNOS expression was assayed by western blotting of the aortic homogenate. As shown in Figure 5A, HF caused the reduction of eNOS expression as observed by a weaker signal versus control band. DMC and ATV treated group showed more intense bands indicating increased eNOS expression. Protein levels of GAPDH remained unaltered demonstrating equal protein loading. A summary of these data was presented in Figure 5B.

\section{Discussion}

The principal finding of this study was that DMC could partially protect the aorta from HF-induced endothelial dysfunction via upregulating the expression of eNOS. And we discovered that DMC failed to improve the impairment of contraction of aorta induced by HF on account of the change of $\mathrm{K}_{\mathrm{ATP}}$ channels on structure and/or function.

It has been recognized that vascular smooth muscle cells contribute to the contracting function while the endothelium modulates this contraction via the release of relaxing factors. In this study we applied PE and ACh to investigate the contraction and relaxation of aorta respectively after HF diet with or without DMC and ATV intervention. PE is a $\alpha_{1}$-adrenergic receptor agonist used extensively as a vasoconstrictor [13]. ACh is an endothelial-dependent vasodilator and a well-known method for monitoring the status of the vascular endothelium [14]. Our result demonstrated that HF diet induced significant attenuation of the vasocontraction and relaxation, indicating impaired vascular responsiveness and elasticity caused by the injury of smooth muscle layer as well as endothelium, which was consistent with those previously shown $[1-3,6]$. Treatment with

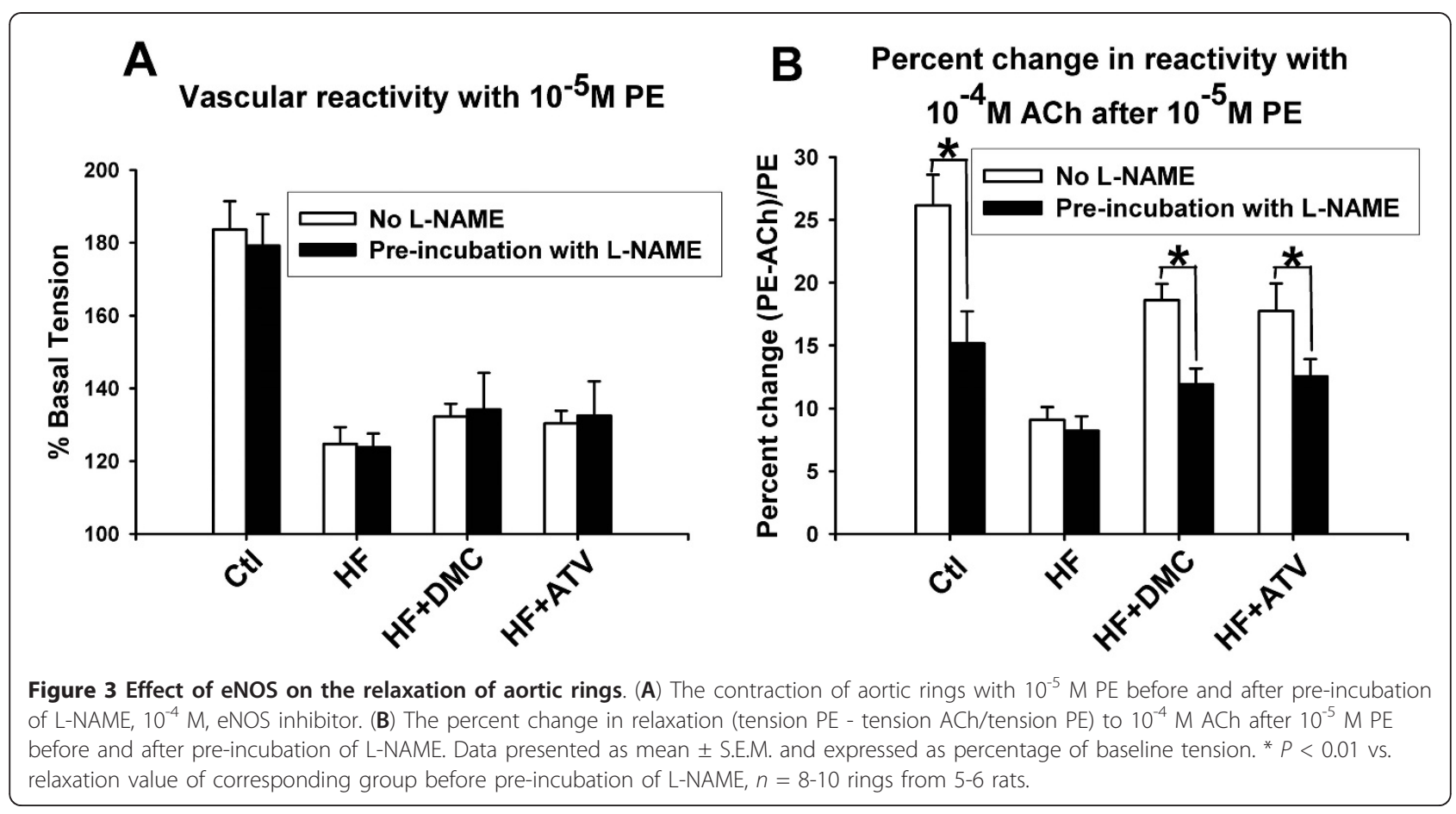




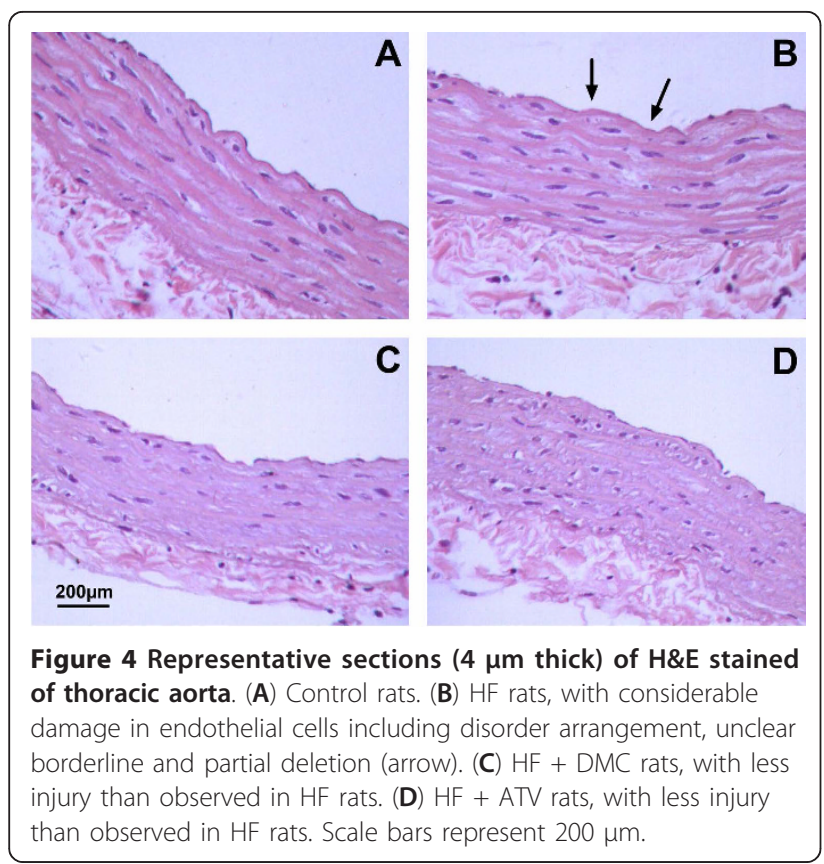

DMC failed to mitigate the contraction of smooth muscle cells but it restored vascular endothelial dilation function. NO, as the most important endogenous vasodilator agent, is generated by the catalysis of L-arginine by eNOS which is a critical regulator of vascular tone [15]. Therefore, it is necessary to investigate the function of eNOS in aortas of different groups. Employment of a non-specific NOS inhibitor (L-NAME) indicated the participation of eNOS in vasorelaxation in DMC treated group as well as control rats. However HF diet impacted the function of eNOS via a certain mechanism therefore resulted in the abolishment of relaxation. Further evidence was obtained by the expression of eNOS in western blot analysis. Treatment with DMC recovered the decrease of eNOS expression induced by HF diet. We infer that the activity and expression of eNOS were involved in the mechanism of DMC for mitigation. Similar results were found in histopathologic examination with endothelial damage in HF rats. This pathologic damage was not found in rats with DMC treatment. Therefore we conclude that DMC protected, at least in part, the endothelial dysfunction of aorta in high-fat diet rats. Lipid-modulating drugs statins (HMGCoA reductase inhibitors) are a milestone to lower cholesterol levels in blood and become one of the most powerful pharmacological strategies in the treatment of cardiovascular diseases [16]. Statins could relax vascular tone importantly by endothelium-dependent pathway [17]. It exerts cholesterol-independent vasoprotective effects by upregulating endothelial nitric oxide synthase and decreasing superoxide production [18]. In this study atorvastatin (ATV) was applied as a positive control to

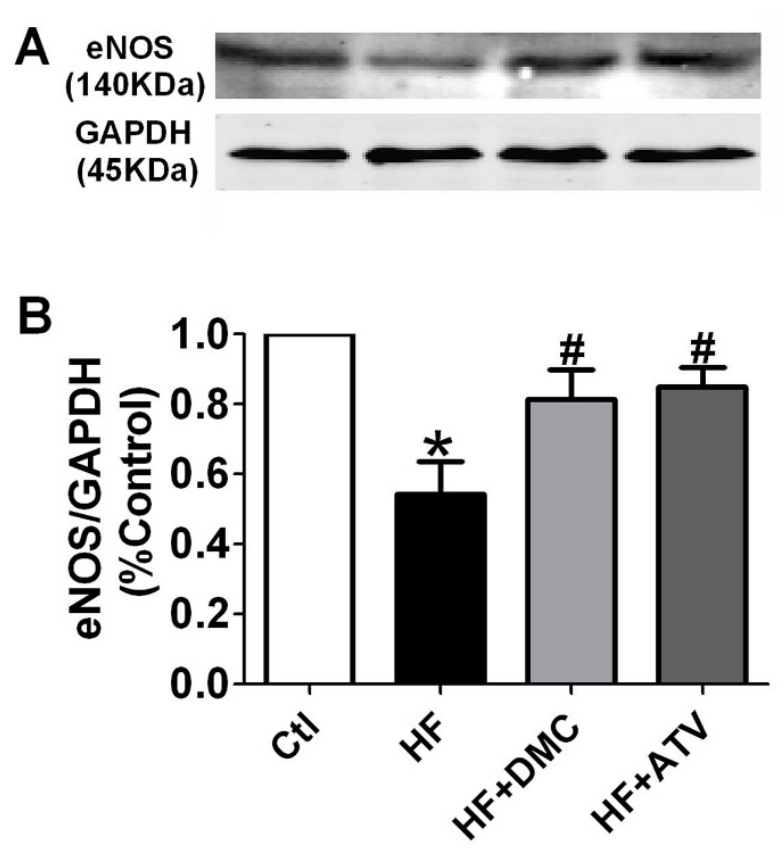

Figure 5 High-fat-induced attenuation of eNOS protein expression in thoracic aorta and mitigation by DMC and ATV. (A) Representative examples of western blot assay of eNOS (140 $\mathrm{kDa}$ ) protein are shown including GADPH expression (45 kDa) as a loading control. (B) Statistical bar graph indicates the result of densitometric analysis of the bands as normalized to the quantity of GADPH protein. These ratios were normalized to control. ${ }^{*} P<0.01$ vs. control group, \# $P<0.05$ vs. HF, $n=4$

DMC. Our results were consistent with these previous reports and ATV has the same protective effect on endothelial dysfunction as DMC.

$\mathrm{K}^{+}$channels play an important role in the regulation of vascular function through inflowing or outflowing $\mathrm{K}^{+}$ and $\mathrm{Ca}^{2+}$ current. There are at least four different classes of $\mathrm{K}^{+}$channels, including inward rectifier $\mathrm{K}^{+}$ channels $\left(\mathrm{K}_{\mathrm{IR}}\right)$, ATP-sensitive $\mathrm{K}^{+}$channels $\left(\mathrm{K}_{\mathrm{ATP}}\right)$, voltage-gated $\mathrm{K}^{+}$channels $\left(\mathrm{K}_{\mathrm{V}}\right)$, and large conductance $\mathrm{Ca}^{2}$ ${ }^{+}$-activated $\mathrm{K}^{+}$channels $\left(\mathrm{BK}_{\mathrm{Ca}}\right)$. It was proposed that blockade of $\mathrm{K}_{\mathrm{ATP}}, \mathrm{K}_{\mathrm{V}}$, and $\mathrm{BK}_{\mathrm{Ca}}$, which lead to membrane depolarization, the activation of $\mathrm{Ca}^{2+}$ channels, an increased $\mathrm{Ca}^{2+}$ influx, and vasoconstriction ensues [19-21]. In this study, $\mathrm{K}^{+}$channel blockers including 4$\mathrm{AP}, \mathrm{GLYB}$, TEA for $\mathrm{K}_{\mathrm{V}}, \mathrm{K}_{\mathrm{ATP}}$, and $\mathrm{BK}_{\mathrm{Ca}}$ respectively were employed to determine the contribution of particular $\mathrm{K}^{+}$channels in vascular tone of aortic rings. The results revealed that $\mathrm{BK}_{\mathrm{Ca}}$ channel were not involved in the contraction of aortic rings and $K_{V}$ channels were involved in this process but played the same role in all groups, indicating that the mechanism of the attenuation of aortic contraction in HF and DMC and ATV treated rats was not relevant to $\mathrm{BK}_{\mathrm{Ca}}$ and $\mathrm{K}_{\mathrm{V}}$ channels. The blockade of $\mathrm{K}_{\mathrm{ATP}}$ channel significantly enhanced 
the vasocontraction of aortic rings in control rats but not in the other groups. The results demonstrated that in normal condition $\mathrm{K}_{\mathrm{ATP}}$ channels participated in the constriction process of aorta, but their structure and/or function were altered in HF model and these alterations were not mitigated by the treatment of DMC and ATV. Fan LH et al. [22] proved that HF diet may impair the function and expression of $\mathrm{K}_{\mathrm{ATP}}$ channels in vascular smooth muscle cells by patch clamp and western blotting, which provides powerful evidence for our results. So we proposed that the impairment of $\mathrm{K}_{\mathrm{ATP}}$ channels might be the mechanism that DMC and ATV cannot restore the dysfunction of contraction of aorta induced by HF. Though it has been reported that pravastatin has a significant beneficial effect during myocardial ischemia, which is provided by $\mathrm{K}_{\mathrm{ATP}}$ channels and NO [23], our results did not show the restoration of ATV on $\mathrm{K}_{\mathrm{ATP}}$ channels impaired by HF model.

DMC abides by jun, chen, zuo, shi (monarch, minister, adjuvant and messenger) and a holistic concept of traditional Chinese medicine formula and is good at treating chronic diseases due to reduced adverse side effects even for long-term application. Here we didn't investigate each component of DMC separately because it destructed the drug interactions. Despite of a compound the quality of DMC can be controlled accurately. Chrysophanol, the criteria of quality control of Rheum Palmatu which is the potent component of DMC, is applied to control the stability of the formula (Pharmacopoeia of the People's Republic of China, 2010). The location and season of plant acquisition and preparation process of DMC were controlled strictly for quality assurance. DMC is a research project having independent intellectual property rights and has been applied extensively in Chinese clinic as a lipid modulating drug for ten years. DMC protects heart function in streptozocin-induced diabetic rats with hyperlipidemia [9]. Our research found the protection of DMC on vascular injury induced by HF diet and provided a powerful evidence for expanding the clinical application of DMC particularly in patients with diabetes mellitus accompanied by hyperlipidemia. Moreover our study disclosed the same protective effect of DMC and ATV on vascular endothelial dysfunction produced by HF diet. Therefore, DMC displays remarkable advantages with lower adverse side effects and provides a new candidate for prevention and therapy of vascular injury induced by hyperlipdiemia.

In our study, we did not obtain the restoration of DMC on the impairment of contraction of aorta. Maybe DMC treatment for a longer period would present an effect with more intensity in vascular reactivity. Furthermore, peripheric arteries such as tail artery and mesenteric artery could present a different effect. Definitely all these need to be further investigated. More importantly, many studies indicated that inducible nitric oxide synthase (iNOS) was relevant to vascular injury [24-26] and oxidative stress induced the expression of iNOS and subsequent generation of high concentration of $\mathrm{NO}$, which could interact with reactive oxygen species (ROS) causing vascular dysfunction [26-28]. The effect of DMC on ROS and iNOS in the process of vasomotion will be elucidated by our future studies.

\section{Conclusions}

The present findings provided the first effort to establish that DMC could partially protect the endothelial dysfunction of aorta in HF diet rats via upregulating the expression of eNOS.

\section{Abbreviations}

DMC: Daming capsule; HF: High-fat; eNOS: Endothelial nitric oxide synthase; $K_{\text {ATP: }}$ ATP-sensitive $K^{+}$channels; ATV: Atorvastatin; NO: Nitric oxide; LDL: Low density lipoprotein; PE: Phenylephrine; ACh: Acetylcholine; 4-AP: 4amionpyridine; TEA: Tetraethylammonium; GLYB: Glyburide; L-NAME: NGNitro-L-arginine Methyl Ester; $K_{\mathbb{R}}$ : Inward rectifier $K^{+}$channels; $K_{V}$ : Voltagegated $\mathrm{K}^{+}$channels; $\mathrm{BK}_{\mathrm{Ca}}$ : Large conductance $\mathrm{Ca}^{2+}$-activated $\mathrm{K}^{+}$channels; iNOS: Inducible nitric oxide synthase; ROS: Reactive oxygen species.

\section{Acknowledgements}

This study was supported in part by the New Century Excellent Talents in University supported by the Ministry of Education of China (no. NCET-08), the Funds for Creative Research Groups of The National Natural Science Foundation of China (81121003), and National Postdoctoral Science Foundation (20090451023).

\section{Author details}

${ }^{1}$ Department of Pharmacology, (the State-Province Key Laboratory of Biomedicine and Pharmaceutics), and Key Laboratory of Cardiovascular Research, Ministry of Education, Harbin 150086, Peoples' Republic of China. ${ }^{2}$ Department of Pathology, Harbin Medical University, Harbin 150081, Peoples' Republic of China.

\section{Authors' contributions}

RZ: Designing and performing the study, analyzing the data and preparing the manuscript. HN: Performing the study and analyzing the data. NW, LS and $Y X$ : Participating in the ring study. RZ, XB: Performing the histological examination. YY: Establishing the animal model. JA: Supervising the work, providing the grant, evaluating the data, correcting the manuscript and coordinating the study. BY: Supervising the work, providing the grant and coordinating the study. All authors read and approved the final manuscript.

\section{Competing interests}

Professor Baofeng Yang in the department of Pharmacology of Harbin Medical University holds the patent on the formula of DMC (Patent No.: ZL03109063.X) and authorized Harbin Yida Ltd to produce the formulation. There is no competing interest between them. The authors declare that they have no competing interests.

Received: 1 November 2011 Accepted: 24 March 2012

Published: 24 March 2012

\footnotetext{
References

1. Napoli C, Martin-Padura I, de Nigris F, Giorgio M, Mansueto G, Somma P, Condorelli M, Sica G, De Rosa G, Pelicci P: Deletion of the p66Shc longevity gene reduces systemic and tissue oxidative stress, vascular cell apoptosis, and early atherogenesis in mice fed a high-fat diet. Proc Natl Acad Sci USA 2003, 100(4):2112-2116.

2. Magne J, Huneau JF, Tsikas D, Delemasure S, Rochette L, Tome D, Mariotti F: Rapeseed protein in a high-fat mixed meal alleviates
} 
postprandial systemic and vascular oxidative stress and prevents vascular endothelial dysfunction in healthy rats. J Nutr 2009, 139(9):1660-1666.

3. Barringer TA, Hatcher L, Sasser HC: Potential Benefits on Impairment of Endothelial Function after a High-fat Meal of 4 weeks of Flavonoid Supplementation. Evid Based Complement Alternat Med 2008.

4. Yang N, Ying C, Xu M, Zuo X, Ye X, Liu L, Nara Y, Sun X: High-fat diet upregulates caveolin-1 expression in aorta of diet-induced obese but not in diet-resistant rats. Cardiovasc Res 2007, 76(1):167-174.

5. Taylor AM, Li F, Thimmalapura P, Gerrity RG, Sarembock IJ, Forrest $S$, Rutherford S, MCNamara CA: Hyperlipemia and oxidation of LDL induce vascular smooth muscle cell growth: an effect mediated by the HLH factor Id3. J Vasc Res 2006, 43(2):123-130.

6. Li R, Xu M, Wang X, Wang Y, Lau WB, Yuan Y, Yi W, Wei X, Lopez BL, Christopher TA, et al: Reduced vascular responsiveness to adiponectin in hyperlipidemic rats-mechanisms and significance. J Mol Cell Cardiol 2010, 49(3):508-515.

7. Brayden JE, Earley S, Nelson MT, Reading S: Transient receptor potential (TRP) channels, vascular tone and autoregulation of cerebral blood flow. Clin Exp Pharmacol Physiol 2008, 35(9):1116-1120.

8. Martens JR, Gelband CH: Ion channels in vascular smooth muscle: alterations in essential hypertension. Proc Soc Exp Biol Med 1998, 218(3):192-203.

9. Ai J, Yan X, Zhao L, Lu Y, Liang F, Cai B, Li G, Lu Y, Yang B: The protective effect of Daming capsule on heart function in streptozocin-induced diabetic rats with hyperlipidemia. Biol Pharm Bull 2009, 32(8):1354-1358.

10. Jing A, Li-Mei Z, Yan-Jie L, Ben-Zhi C, Yong Z, Bao-Feng Y: A randomized, multicentre, open-label, parallel-group trial to compare the efficacy and safety profile of daming capsule in patients with hypercholesterolemia. Phytother Res 2009, 23(7):1039-1042.

11. Ai J, Wang LH, Zhang R, Qiao GF, Wang N, Sun LH, Lu GY, Sun C, Yang BF: Protective effect of the daming capsule on impaired baroreflexes in STZ-induced diabetic rats with hyperlipoidemia. BMC Complement Altern Med 2010, 10:80.

12. Zhang R, Ghosh SN, Zhu D, North PE, Fish BL, Morrow NV, Lowry T, Nanchal R, Jacobs ER, Moulder JE, et al: Structural and functional alterations in the rat lung following whole thoracic irradiation with moderate doses: injury and recovery. Int J Radiat Biol 2008, 84(6):487-497.

13. Scicluna JK, Mansart A, Ross JJ, Reilly CS, Brown NJ, Brookes ZL: Reduced vascular response to phenylephrine during exposure to lipopolysaccharide in vitro involves nitric oxide and endothelin 1. Shock 2008, 29(3):417-421.

14. Kasprzak JD, Klosinska M, Drozdz J: Clinical aspects of assessment of endothelial function. Pharmacol Rep 2006, 58(Suppl):33-40.

15. Forstermann U: Nitric oxide and oxidative stress in vascular disease. Pflugers Arch 2010, 459(6):923-939.

16. Endo A: A historical perspective on the discovery of statins. Proc Jpn Acad Ser B Phys Biol Sci 2010, 86(5):484-493.

17. Sonmez Uydes-Dogan B, Topal G, Takir S, Ilkay Alp F, Kaleli D, Ozdemir O: Relaxant effects of pravastatin, atorvastatin and cerivastatin on isolated rat aortic rings. Life Sci 2005, 76(15):1771-1786.

18. Endres M, Laufs U: Effects of statins on endothelium and signaling mechanisms. Stroke 2004, 35(11 Suppl 1):2708-2711.

19. Ko EA, Han J, Jung ID, Park WS: Physiological roles of $K+$ channels in vascular smooth muscle cells. J Smooth Muscle Res 2008, 44(2):65-81.

20. Borbouse L, Dick GM, Payne GA, Berwick ZC, Neeb ZP, Alloosh M, Bratz IN, Sturek M, Tune JD: Metabolic syndrome reduces the contribution of K + channels to ischemic coronary vasodilation. Am J Physiol Heart Circ Physiol 2010, 298(4):H1182-H1189.

21. Hodnett BL, Xiang L, Dearman JA, Carter CB, Hester RL: K(ATP)-mediated vasodilation is impaired in obese Zucker rats. Microcirculation 2008, 15(6):485-494.

22. Fan $L H$, Tian $H Y$, Yang ML, Ma AQ, Hu Z, Bai XJ, Cao YX: High-fat diet may impair K(ATP) channels in vascular smooth muscle cells. Biomed Pharmacother 2009, 63(2):165-170.

23. Kawabata H, Ryomoto T, Ishikawa K: Role of cardiac ATP-sensitive $\mathrm{K}+$ channels induced by HMG CoA reductase inhibitor in ischemic rabbit hearts. Hypertens Res 2001, 24(5):573-577.

24. Behr D, Rupin A, Fabiani JN, Verbeuren TJ: Distribution and prevalence of inducible nitric oxide synthase in atherosclerotic vessels of long-term cholesterol-fed rabbits. Atherosclerosis 1999, 142(2):335-344.
25. Kibbe M, Billiar T, Tzeng E: Inducible nitric oxide synthase and vascular injury. Cardiovasc Res 1999, 43(3):650-657.

26. Olukman M, Orhan CE, Celenk FG, Ulker S: Apocynin restores endothelial dysfunction in streptozotocin diabetic rats through regulation of nitric oxide synthase and NADPH oxidase expressions. J Diabetes Complications 2010, 24(6):415-423.

27. Rocha JT, Hipólito UV, Callera GE, Yogi A, Neto Filho Mdos A, Bendhack LM, Touyz RM, Tirapelli CR: Ethanol induces vascular relaxation via redoxsensitive and nitric oxide-dependent pathways. Vascul Pharmacol 2012, 56(1-2):74-83.

28. Kvietys $P R$, Granger DN: Role of reactive oxygen and nitrogen species in the vascular responses to inflammation. Free Radic Biol Med 2012, 52(3):556-592.

\section{Pre-publication history}

The pre-publication history for this paper can be accessed here: http://www.biomedcentral.com/1472-6882/12/21/prepub

doi:10.1186/1472-6882-12-21

Cite this article as: Zhang et al: Daming capsule restores endothelial dysfunction induced by high-fat diet. BMC Complementary and Alternative Medicine 2012 12:21.

\section{Submit your next manuscript to BioMed Central and take full advantage of:}

- Convenient online submission

- Thorough peer review

- No space constraints or color figure charges

- Immediate publication on acceptance

- Inclusion in PubMed, CAS, Scopus and Google Scholar

- Research which is freely available for redistribution

Submit your manuscript at www.biomedcentral.com/submit
Ciomed Central 